\title{
Editorial
}

\section{Lo sustentable como aspecto clave en la creación de archivos sonoros y audiovisuales digitales DOI: http://dx.doi.org/10.22201/iibi.0187358xp.2017.72.57821}

$\mathrm{M}_{\mathrm{i}}^{\mathrm{i}}$ iles de personas vieron y escucharon el asesinato de John F. Kennedy (1963); el momento en que el primer ser humano pisó la Luna (1969); el instante en que explotó el transbordador espacial Challenger (1986); la masacre de la Plaza en Tiananmen (1989); la caída del muro de Berlín (1989); los atentados del 11 de septiembre a las Torres Gemelas de Nueva York (2001); el terremoto y el tsunami de Japón (2011); las marchas de protesta por la desaparición forzada de los 43 estudiantes normalistas de Ayotzinapa, Guerrero (2014) y los atentados de París (2015), entre otros acontecimientos que han estremecido, asombrado e indignado a la sociedad. Estos y otros hechos, que dan cuenta de días de gloria y de oscuridad, son parte de la historia reciente que ha sido documentada con imágenes y sonidos. Las grabaciones sonoras y audiovisuales son los testimonios y recursos de información a través de los cuales nos conocerán y juzgarán las generaciones del futuro. La permanencia de documentos sonoros y audiovisuales, a través del tiempo, es uno de los mayores desafíos de los bibliotecarios, documentalistas, archivistas y los profesionales de la información que tienen la responsabilidad de salvaguardar la memoria libraria y documental de la humanidad.

Esta encomienda cobró trascendencia desde que la Unesco publicó en 1980 la Recomendación sobre la Salvaguardia y la Conservación de las Imágenes en Movimiento, y reconoció que los documentos audiovisuales, en los cuales se incluyen los sonoros, forman parte de la herencia de la humanidad, por lo que es necesario adoptar medidas jurídicas, administrativas y técnicas para salvaguardarlos. A partir de entonces se han impulsado 


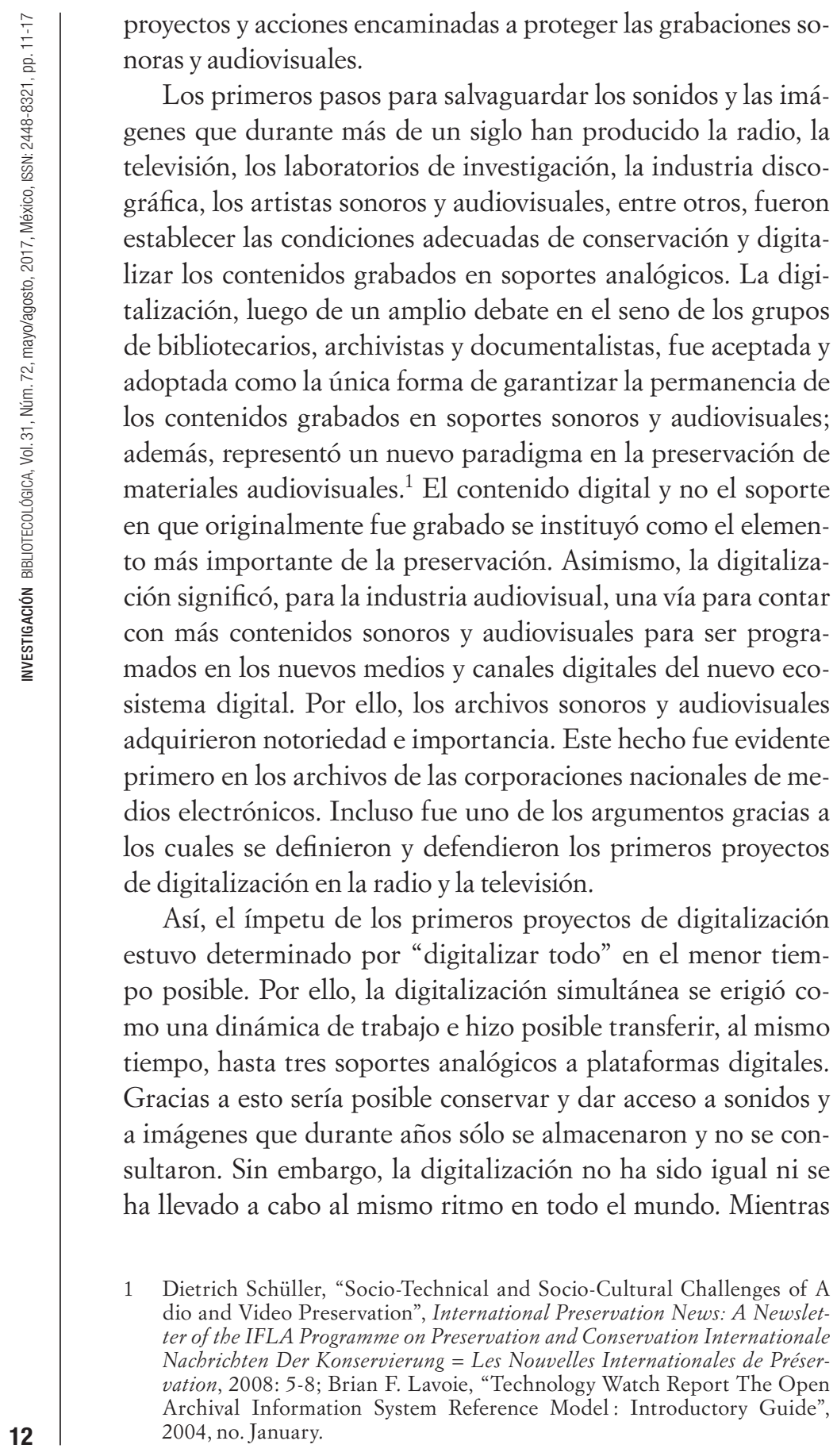


algunos archivos habían iniciado magnos proyectos de digitalización, otros ni siquiera contaban con los recursos básicos para conservar en condiciones adecuadas sus colecciones analógicas. Esta desigual situación marcó la aparición de la brecha digital entre los archivos.

La magnitud de los soportes sonoros y audiovisuales que deben ser digitalizados propició que los archivistas reconsideraran la idea de digitalizar todo. Fue necesario priorizar la digitalización de los documentos. La selección como proceso previo a la digitalización fue cada vez más determinante en las acciones para preservar las grabaciones sonoras. Por ello, la Asociación de Archivos Sonoros y Audiovisuales (IASA) y la Federación de Archivos de Televisión (FIAT) establecieron criterios para priorizar la digitalización de sus documentos sonoros y audiovisuales. La antigüedad, rareza, unicidad, obsolescencia, derechos de autor, así como el valor histórico, social, educativo y cultural de los documentos fueron las variables que determinaron las prioridades para digitalizar.

Por lo tanto, la impronta en los archivos en los últimos años ha sido seleccionar los documentos sonoros y audiovisuales cuyos contenidos deban ser priorizados para ser digitalizados. No obstante estos esfuerzos, se sabe por investigaciones recientes que cuantiosas cantidades de horas de sonidos e imágenes se perderán en los próximos 15 años, por lo que la inteligencia empleada en los procesos de selección y la determinación con que se lleven a cabo los proyectos de digitalización definirán los contenidos sonoros y audiovisuales que preservaremos para las sociedades del futuro. Este escenario nos lleva a considerar que es probable que en la próxima década las investigaciones se dediquen a estudiar las grabaciones sonoras y audiovisuales que desaparecieron irremediablemente.

Sin embargo, para los archivos que han digitalizado todas o una parte de sus colecciones el camino tampoco es sencillo. La digitalización es sólo la punta del iceberg de una serie de cambios radicales. El tránsito del archivo que salvaguarda soportes analógicos al archivo digital es inminente. Día a día se acopian, acumulan, conservan, administran y se consultan miles contenidos digitales, provenientes de la digitalización o de origen digital, a través de archivos digitales. Para preservar colosales cantidades de información digital sonora y audiovisual el enfoque 
contemporáneo de la preservación digital se ha encaminado a generar estándares que establezcan los formatos para la preservación digital de documentos sonoros y audiovisuales, a diseñar arquitecturas y esquemas de metadatos interoperables, a diseñar e incorporar modelos como el OAIS (Open Archival Information System) que ayudan a comprender desde la perspectiva conceptual qué es un archivo digital y a utilizar la migración y la emulación como métodos de preservación digital, entre otros.

Más allá de estas relevantes aportaciones, la preservación digital de contenidos sonoros y audiovisuales es una tarea que enfrenta múltiples y complejos problemas, entre ellos saber que no existe una tecnología única para preservar grandes volúmenes de información digital y que la sustitución de hadware y software es cíclica, determinada por periodos de vida cortos comparados con los que tuvieron los soportes analógicos. A su vez, la entrada en desuso y el desecho de tecnología genera que se acumule basura tecnológica, cuyos efectos son nocivos para la salud e inciden en el deterioro del medio ambiente.

A esta situación se suma que los recursos económicos son exiguos o nulos y no son suministrados de forma continua. En muchas ocasiones, los archivos obtienen recursos extraordinarios para digitalizar sus colecciones y después difícilmente se mantiene el recurso económico porque se carece de modelos adecuados de financiamiento que garanticen el acceso y la conservación de los documentos digitales. Además, no se alcanzan a comprender la magnitud ni la importancia de la preservación digital como una tarea permanente. $\mathrm{Y}$ en muchos casos priva la complacencia con el desarrollo de prácticas tradicionales y el temor de que el acceso y la preservación digital sean demasiado complicados para abordarlos. ${ }^{2}$ A lo que se suma que los archivos son botines políticos y se designa al frente de las instituciones a personal que carece del conocimiento y de la sensibilidad necesaria para sostener los trabajos en el archivo. Panorama al que se adhiere la confusión y/ o falta de coordinación de funciones y responsabilidades entre las instituciones involucradas en la conservación y el acceso digital, creando con ello silos digitales de instituciones que cuentan con soluciones

2 The Blue Ribbon Task Force, Sustaining the Digital Investment: Issues and Challenges of Economically Sustainable Digital Preservation. The Blue Ribbon Task Force, 2008. http://brtf.sdsc.edu/biblio/BRTF_Interim_Report.pdf 
tecnológicas únicas que raramente se comparten. Por otra parte, es notoria la falta de propuestas creativas para reutilizar de forma sistemática los documentos en apoyo a tareas educativas, culturales y sociales.

Con base en el contexto anterior, la preservación digital es una tarea compleja que va más allá de garantizar la continuidad de la información digital, del manejo de los datos y de su integración en el ciclo de vida del objeto de información. El objetivo de la preservación digital debe hacer que un objeto digital permanezca en el tiempo independientemente del entorno tecnológico. Por ello, todas las acciones económicas, jurídicas, ambientales, sociales, organizacionales y de reaprovechamiento que se lleven a cabo en el presente deberán diseñarse pensando en mantener los contenidos (media y metadata) en el porvenir, bajo una perspectiva sustentable, que según esta perspectiva debe ser la meta a alcanzar por todo archivo digital sonoro y audiovisual.

La perspectiva sustentable debe estar presente en el momento mismo en que se diseña un archivo digital y no puede ser la misma solución para todos los archivos. Cada archivo tiene condiciones y problemas diferentes que se deben identificar y analizar con una perspectiva de futuro. Probablemente en algunos casos se identifique que ciertos roles y funciones han quedado en desuso y sea necesario actualizar y en consecuencia adquirir nuevas habilidades. En otros, probablemente sea indispensable incorporar profesionales de diversas disciplinas que atiendan necesidades específicas del archivo. Pero también ha de tomarse en consideración que el archivista, documentalista o profesional de la información debe ser el responsable de organizar y gestionar las tareas de preservación en un archivo. ${ }^{3}$ Es necesario que los profesionales que dirigen un archivo sonoro y audiovisual conozcan y posean la sensibilidad suficiente para comprender que la preservación es una actividad permanente, que cada paso que se dé tendrá una repercusión en el futuro y que la continuidad y coherencia son necesarias para que el archivo sea sustentable.

Estas acciones han de ser analizadas pensando en los usuarios actuales y futuros del archivo. El ejercicio prospectivo

3 Ray Edmondson, "Filosofía y principios de los Archivos Audiovisuales". Unesco, 2004. 
encaminado a saber quiénes serán los usuarios del futuro es complejo y necesario para el diseño de servicios y productos de información que sean de utilidad para la sociedad. Por ello, la precisión con que se establezcan los derechos de autor de las colecciones, desde el momento mismo en que un documento llega al archivo, será un factor necesario para fomentar e incrementar el acceso abierto de los documentos.

Por otra parte, se ha de considerar que todo uso de los documentos confiere valor social al archivo y, a su vez, ayuda a que se comprenda que es necesario sostener el presupuesto de forma permanente. No obstante, el hecho de contar con recursos económicos de forma sistemática no exime al archivo de adoptar una actitud proactiva y crear mecanismos para recaudar y autogenerar recursos económicos. El reconocimiento social y la incorporación de nuevos actores que ayuden a sostener económicamente las tareas de preservación digital son un componente indispensable de una perspectiva sustentable. Además, para asentar un archivo digital sustentable, sobre todo para las instituciones públicas, es necesario que se establezcan planes de colaboración para la puesta en marcha de infraestructura compartida que reduzca costos y amplíe los beneficios de la tecnología a más instituciones. Otro aspecto a considerar en la creación de un archivo digital sustentable es fomentar el conocimiento colaborativo entre las instituciones que tienen archivos digitales y en establecer las medidas para minimizar el daño que la tecnología produce sobre la salud y el medio ambiente. El uso de energías renovables en los archivos digitales sonoros y audiovisuales deberá ser el sello que dejemos los archivistas para el futuro.

Bajo estas y otras consideraciones, la construcción de los archivos digitales del porvenir deberá basarse en una perspectiva sustentable gracias a la cual se garantice la conservación y el acceso a los documentos sonoros y audiovisuales que hemos generado como sociedad y a través de los cuales tenderemos un puente de comunicación con las generaciones del futuro.

Perla Olivia Rodríguez Reséndiz 
EDITORIAL

Para citar este texto:

Rodríguez Reséndiz, Perla Olivia. 2017. "Lo sustentable como aspecto clave en la creación de archivos sonoros audiovisuales digitales". Investigación Bibliotecológica: Archivonomía, Bibliotecología e Información 72 (31): 11-17.

http://dx.doi.org/10.22201/iibi.0187358xp.2017.72.57821 